\title{
REVITALISASI NOVEL BURAK SILUMAN KARYA MOHAMAD AMBRI KE DALAM CERPEN “BURAK SILUMAN” KARYA AJIP ROSIDI
}

\author{
Sumiyadi \\ FPBS Universitas Pendidikan Indonesia \\ email: sumiyadi@upi.edu
}

\begin{abstract}
Abstrak
Penelitian ini bertujuan mendeskripsikan aspek, pola, dan tujuan revitalisasi novel Burak Siluman ke dalam cerpen Burak Siluman. Sumber data penelitian adalah novel Burak Siluman karya Mohamad Ambri dalam buku Urang Desa (Balai Pustaka Jakarta, 1950) dan cerpen Burak Siluman karya Ajip Rosidi (Nuansa Bandung, 2008). Analisis data menggunakan teori struktural semiotik Greimas. Hasil penelitian sebagai berikut. Pertama, aspek novel yang direvitalisasi adalah tema cerita siluman sebagai mitos masyarakat Sunda. Kedua, revitalisasi terklasifikasi ke dalam pola rekonstruksi dan pola transfer, yaitu dengan melakukan eksternalisasi. Untuk kepentingan itulah Ajip Rosidi mengalihbahasakan novel klasik Sunda tersebut ke dalam bahasa nasional. Ketiga, revitalisasi dengan mengalihwahanakan novel Sunda ke dalam cerpen Indonesia bertujuan untuk mengonservasi cerita Sunda yang berkaitan dengan mitos alam siluman.
\end{abstract}

Kata kunci: revitalisasi, mitos, rekonstruksi, transfer, eksternalisasi

\section{THE REVITALIZATION OF MOHAMAD AMBRI'S NOVEL BURAK SILUMAN INTO AJIP ROSIDI'S SHORT STORY BURAK SILUMAN}

\begin{abstract}
This study aims to describe the aspect, pattern, and purpose of the revitalization of the novel Burak Siluman into the short story Burak Siluman. The data sources were Mohamad Ambri's novel Burak Siluman in the book Urang Desa (Balai Pustaka Jakarta, 1950) and Ajip Rosidi's short story Burak Siluman (Nuansa Bandung, 2008). The data analysis used Greimas's structural theory of semiotics. The findings are as follows. First, the aspect of the novel revitalized is the theme of ghost stories as Sundanese people's myth. Second, the revitalization is classified into reconstruction and transfer patternsby performing the externalization. For that purpose, Ajip Rosidi translates a Sundanese classic novel into the national language. Third, the revitalization by converting a Sundanese novel into an Indonesian short story aims to conserve Sundanese stories about the myth of the ghost world.
\end{abstract}

Keywords: revitalization, myth, reconstruction, transfer, externalization

\section{PENDAHULUAN}

Revitalisasi adalah "proses, perbuatan menghidupkan kembali atau menggiatkan kembali" (KBBI, 2013: 1172). Kebudayaan dapat direvitalisasi jika budaya tersebut dipertimbangkan memiliki kepentingan signifikan bagi komunitas pendukungnya
(Pudentia, 2010:1). Karya sastra merupakan salah satu produk budaya, yang memungkinkan untuk direvitalisasi.

Berkaitan dengan revitalisasi karya sastra, penulis tertarik untuk meneliti cerpen berjudul "Burak Siluman" karya Ajip Rosidi. Cerpen tersebut merupakan 
karya sastra Indonesia hasil alih bahasa Ajip Rosidi dari khazanah sastra Sunda karya Mohamad Ambri (1882-1936) berjudul sama, yaitu novel Burak Siluman (pertama kali terbit tahun 1932). Menurut Kurnia (2008), Mohamad Ambri merupakan pengarang Sunda yang kerap kali menulis karya sastra mengenai siluman atau makhluk halus. Demikian pula novel Burak Siluman berkisah tentang seorang gadis yang terperangkap di antara dua alam, yaitu alam makhluk manusia dan alam siluman atau makhluk halus.

Ajip Rosidi (lahir tahun 1938) setakat ini telah melahirkan lebih dari 110 judul buku dengan tajuk beragam, seperti kumpulan cerpen, kumpulan puisi, novel/ roman, drama, transformasi cerita rakyat dan wayang, bacaan anak-anak, kumpulan humor, esai dan kritik, polemik, memoar, bunga rampai, buku terjemahan, dan biografi/autobiografi. Ajip Rosidi juga termasuk sastrawan atau budayawan yang banyak berkiprah dalam dunia penerbitan, pendidikan, dan kebudayaan, Bahkan, dia pernah menjadi profesor tamu pada Osaka Gaikokugo Daigaku di Jepang (1981-2003) dan pada tahun 2011dianugerahi gelar Dr. H.C. dalam bidang budaya dari Fakultas Sastra Universitas Pajajaran. Padahal, seperti otografi yang ditulisnya, Ajip Rosidi Hidup Tapa Ijazah (2008a) karena dengan sengaja tidak menamatkan SMA-nya. Dia hidup dengan mengandalkan banyak membaca dan menulis hingga kini.

Cerpen "Burak Siluman" diteliti untuk menunjukkan bahwa Ajip Rosidi peduli terhadap khazanah sastra Indonesia yang terwujud dalam sastra-sastra daerah di seluruh Nusantara. Keanekaragaman budaya yang tecermin dalam karya sastra itu hanya dapat dipahami secara nasional apabila menggunakan bahasa nasional pula. Oleh sebab itu, alih bahasa dan alih wahana sastra dari bahasa daerah ke dalam bahasa Indonesia merupakan suatu keniscayaan. Terlebih-lebih, alih bahasa sastra berkaitan erat dengan revitalisasi. Pemahaman revitalisasi yang relevan dalam tulisan ini adalah proses, cara, atau upaya menghidupkan kembali sebuah tradisi, misalnya tradisi atau sastra daerah dalam kehidupan masyarakat pemilik atau pendukungnya (Adnan, 2015:48).

Menurut Supanggah (2008), revitalisai dapat dilakukan dengan pola rekonstruksi, refungsionalisasi, representasi, reformasi, reinterpretasi, reorientasi, dan rekreasi. Rekonstruksi dilakukan terhadap produk seni yang sudah hilang dari peredaran, namun karena dianggap memiliki nilai yang penting bagi masyarakat, produk seni tersebut sengaja dihidupkan dan digiatkan kembali. Refungsionalisasi dilakukan dengan menambah, mengembangkan, mengganti, atau memberi fungsi yang baru terhadap produk seni yang direvitalisasi. Representasi dilakukan dengan menyajikan kembali produk seni tersebut secara variatif. Reformasi dilakukan dengan mengubah format atau bentuk produk seni dari yang lama ke bentuknya yang baru. Reinterpretasi dilakukan dengan memberi tafsir atau makna baru terhadap produk seni. Reorientasi dilakukan dengan menggeser patron lama ke patron yang baru, sedangkan rekreasi adalah membuat atau menciptakan produk seni baru yang bertitik tolak dari produk seni lama.

Sementara itu menurut World Bank (1998:9), pola revitalisasi dapat mengikuti langkah-langkah berikut: rekognisi dan identifikasi, validasi, perekaman dan dokumentasi, penyimpanan dokumen, transfer (sosialisasi, eksternalisasi, internalisasi), dan diseminasi. Berkaitan dengan pola transfer dapat dijelaskan bahwa suatu tradisi lisan, seperti cerita rakyat mengenai siluman, dapat dipindahkan dengan cara disosialisasikan kepada pihak terdekat (keluarga atau murid), diinternalisasikan atau dikonversi dalam bentuk teks verbal tertulis, audio, atau audio visual sehingga dapat dikuasai oleh 
komunitasnya. Pola transfer juga dapat dilakukan secara lebih luas dengan cara tradisi atau produk seni tersebut dieksternalisasi dalam bentuk wahana lain, misalnya mengalihbahasakan produk seni daerah agar dapat diapresiasi oleh masyarakat yang lebih luas.

Setelah data dikaji dengan memperhatikan aspek yang direvitalisasi, penulis akan berupaya menemukan bentuk atau pola revitalisasi dan tujuan pengarang dalam merevitalisasi novel Sunda tersebut.

Penelitian yang relevan dengan tulisan ini pernah dilakukan oleh Rusyana (1979) dengan judul Novel Sunda Sebelum Perang. Akan tetapi, pembahasan tidak terfokus pada revitalisasi dan novel Burak Siluman hanyalah salah satu dari puluhan novel Sunda yang dikaji. Selanjutnya, Pudentia M.P.S.S. (1990) menelaah cerita rakyat Sunda dalam bentuk carita pantun berjudul Lutung Kasarung dan transformasinya dalam novel Indonesia berjudul Purba Sari Ayu Wangi karangan Ajip Rosidi. Penelitian Pudentia telah menunjukkan efek peralihan fokus tokoh dari Lutung Kasarung ke tokoh Purba Sari Ayu Wangi dan ia pun sampai pada simpulan bahwa novel terebut masih memperlihatkan fungsi cerita sebagai penguat tradisi. Sepanjang pengetahuan penulis, penelitian khusus mengenai novel Sunda Burak Siluman dengan alih bahasanya ke dalam sastra Indonesia baru diteliti dalam disertasi peneliti (Sumiyadi, 2010), meskipun baru melihat resepsi pengarangnya dan belum dikaitkan dengan revitalisasi.

Tulisan Kurnia (2008) berjudul "Siluman dalam Sastra Sunda" sangat relevan dengan tulisan ini, meskipun tulisan tersebut merupakan esai di surat kabar dan hanya selintas menyinggung Novel Burak Siluman. Menurut Kurnia (2008), Mohammad Ambri mengarang cerita siluman karena menganut ilmu kebatinan ajian kasumedangan, yang ditekuninya setelah ia mendapatkan pengalaman spiritual ketika berikhtiar untuk kesembuhan istrinya. Is- trinya sakit keras, meskipun telah berkalikali berobat ke dokter. Namun, ternyata istrinya sehat kembali ketika berobat ke seorang dukun di Sumedang. Semenjak itulah Mohamad Ambri kerap menekuni ilmu kebatinan. Simpulan Kurnia didasarkan pada surat-surat Mohamad Ambri semasa hidupnya, yang berhasil dikumpulkan kembali oleh Ajip Rosidi (1996) dalam buku Pancakaki: Kupulan Esey.

\section{METODE}

Penelitian ini menggunakan metode deskriptif analisis dan deskriptif komparatif (Ratna, 2004:42-54). Kedua metode ini tampaknya dapat digabung, sesuai dengan penahapan prosedur kerjanya sehingga menjadi metode deskriptif analisis komparatif.

Teori yang digunakan dalam tulisan ini adalah teori struktural semiotik Greimas yang bertumpu pada skema aktan (Zaimar, 2014: 145-171). Pemanfaatan teori Greimas tampaknya relevan dengan penelitian ini yang akan melihat dinamika tokoh Burak Siluman, baik dalam novel maupun dalam cerpen. Skema aktan bertumpu pada enam aktan, yaitu pengirim, subjek, objek, penolong, penentang, dan penerima. Secara singkat dapat dijelaskan bahwa pengirim adalah aktan yang mempunyai karsa untuk mendapatkan objek. Pengirim dapat berupa seseorang atau sesuatu yang menjadi sumber ide dan berfungsi sebagai penggerak cerita. Pengirimlah yang menimbulkan keinginan bagi subjek untuk mencapai objek. Subjek adalah seseorang atau sesuatu yang ditugasi pengirim untuk mendapatkan objek. Objek adalah seseorang atau sesuatu yang diingini, dicari, dan diburu oleh subjek atas ide si pengirim, yang kemudian akan diserahkan kepada penerima. Penolong adalah seseorang atau sesuatu yang membantu atau mempermudah usaha subjek dalam mencapai objek. Penentang adalah seseorang atau sesuatu yang menghalangi usaha subjek dalam mencari objek, 
sedangkan penerima adalah seseorang atau sesuatu yang menerima objek hasil buruan subjek (Sumiyadi, 2010).

Sumber data penelitian ini adalah novel Sunda berjudul Burak Siluman karya Mohamad Ambri yang terdapat dalam buku Urang Desa (terbitan Balai Pustaka; tahun 1950) dan karya sastra Indonesia karangan Ajip Rosidi, yaitu cerpen "Burak Siluman" (dalam buku Jalan ke Surga atawa Si Kabayan, terbitan Nuansa, cetakan ke-5, tahun 2008). Karena penelitian ini merupakan penelitian kualitatif, alat atau instrumen pengumpul data yang utama adalah peneliti sendiri. Menurut Moleong (2005:168), peneliti merencanakan penelitian, melaksanakan pengumpulan data, menganalisis data, menafsirkan data, hingga pada akhirnya peneliti harus melaporkan penelitian.Dalam hal ini, peneliti merencanakan untuk mengkaji novel Sunda Burak Siluman karya Mohamad Ambri dengan cerpen "Burak Siluman" karya Ajip Rosidi. Setelah sumber data didapat secara lengkap, kemudian peneliti menganalisis keduanya dengan skema aktan Greimas agar aspek, pola, dan tujuan revitalisasi novel Sunda ke dalam cerpen Indonesia dapat dideskripsikan secara jelas.

\section{HASIL DAN PEMBAHASAN Ringkasan Novel dan Cerpen Burak Siluman}

Sebelum dilakukan pembahasan, terlebih dahulu akan disertakan ringkasan novel Novel Burak Siluman Karya Mohamad Ambri dan cerpen Burak Siluman Karya Ajip Rosidi.

\section{Novel Burak Siluman}

Dalam awal novel diceritakan bahwa Nyi Ewi tiba-tiba pingsan, kemudian sakit, padahal sebentar lagi akan dinikahkan. Peristiwa itu menjadi buah bibir masyarakat di sekitarnya, termasuk Ijem, ibunya, Marhadi, dan Mang Ijan. Rumor masyarakat mengenai sakitnya Nyi Ewi dihubungkan dengan cerita makhluk halus, yaitu burak siluman yang memang telah menjadi mitos di kampung tersebut. Dalam obrolan itu, kemudian Mang Ijan didaulat untuk bercerita mengenai burak siluman. Mang Ijan kemudian mengungkapkan cerita burak siluman, yang katanya, didasarkan pada cerita yang pernah didengarnya dari Bapak Saripah.

Mang Ijan berkisah, dulu di Pangalengan (daerah Bandung Selatan) ada seorang petani bernama Ki Jaka dengan istrinya Nyi Sarwini, yang dikaruniai seorang anak perempuan bernama Nyi Asmanah. Pada suatu malam Nyi Asmanah menonton wayang di tempat orang hajatan atau kenduri. Nyi Asmanah tampaknya sangat menggemari pertunjukan wayang.

Nyi Asmanah tumbuh menjadi remaja puteri yang cantik dan rajin bekerja sehingga tidak sedikiti pemuda kampung yang tertarik kepadanya. Namun, entah mengapa Nyi Asmanah sama sekali tidak menaruh hati kepada mereka. Pada suatu hari Nyi Asmanah diajak lagi oleh bapaknya untuk mengunjungi orang yang kenduri. Kebetulan dalam kenduri itu, si tuan rumah menanggap wayang. Nyi Asmanah tentu saja tertarik karena ia tergilagila dengan tokoh Arjuna yang sering kali diceritakan dalam lakon wayang.

Pada saat Nyi Asmanah menonton wayang dalam acara kenduri itu, banyak pemuda yang terpesona dengan kecantikan Nyi Asmanah sehingga setelahnya banyak di antara pemuda itu yang sengaja berkunjung ke Pangalengan untuk bertemu dengan Nyi Asmanah, bahkan ada yang langsung melamarnya. Akan tetapi, berkali-kali Nyi Asmanah menolak lamaran itu. Orang tua Nyi Asmanah cemas karena anaknya tidak segera mau menikah. Ketika ditanya oleh ibunya, Nyi Asmanah mengatakan bahwa ia hanya bersedia dinikahkan dengan Pangeran Dipati Arjuna yang menurutnya lelaki itu sering menemaninya apabila ia pulang 
dari pancuran mandi di sawah. Orang tua Nyi Asmanah sangat khawatir dan menganggap anaknya telah kena pengaruh siluman sehingga harus diobati.

Tibalah pada malam hari, Nyi Asmanah merasa dipanggil oleh Dipati Arjuna sehingga ia turun dari rumahnya dengan sebungkus pakaian dan meninggalkan kedua orang tuanya yang sedang tidur nyenyak. Nyi Asmanah mengikuti arah jalan yang terdapat bunyi alat musik seperti dalam permainan wayang. Akhirnya, Nyi Asmanah bertemu dengan seorang kakek yang menamakan dirinya Kakek Jamungkuk, makhluk siluman yang berkuasa di sana. Setelah mandi Nyi Asmanah merasa menjadi seorang puteri yang bernama Nyai Puteri Mayang Gading. Kemudian ia dinikahkan dengan pangeran siluman. Ketika Nyi Asmanah sedang mengidam tujuh bulan, ia ingin makan buah limau dan kebetulan ada yang mempersembahkan buah limau yang diperoleh dari pohon yang ada di dekat rumahnya di Pangalengan. Setelah makan buah limau itu, ia sadar bahwa dirinya adalah Nyi Asmanah sehingga ia rindu kepada ibu bapaknya. Nyi Asmanah memohon izin kepada pangeran siluman, suaminya, untuk menengok orang tuanya. Suaminya memberikan izin untuk pergi dengan syarat, sebelum lewat tengah malam dia harus sudah kembali. Nyi Asmanah bertemu dengan orang tuanya yang sudah sangat merindukannya. Tidak terasa waktu yang diberikan kepadanya sudah habis sehingga ketika dia kembali ke negeri siluman, suaminya tidak mau menerimanya lagi. Nyi Asmanah menjadi terkatung-katung sebab tidak bisa masuk ke negari siluman dan juga tidak bisa kembali ke alam manusia. Dalam kesengsaraannya itu, Nyi Asmanah melahirkan seorang anak laki-laki yang diberi nama Burak, yang kemudian akan menjadi penggoda wanita yang melanggar larangan, misalnya berlama-lama sendiri bermandi di pancuran. Demikian cerita Mang Ijan. Setelah Mang Ijan selesai bercerita, kemudian dia permisi pulang ke rumahnya.

\section{Cerpen "Burak Siluman"}

Cerpen diawali dengan Nyi Asmanah bangun kesiangan karena menonton wayang golek semalaman yang ditanggap oleh Haji Jakaria. Haji Jakaria menanggap wayang golek karena anak perempuannya yang bernama Halimah menikah dan anak laki-lakinya yang masih kecil sudah waktunya untuk disunat. Halimah adalah teman sepermainan Nyi Asmanah. Keduanya berumur 17 tahun. Nyi Asmanah sendiri belum menikah. Meskipun sebenarnya banyak lelaki yang melamarnya, dia selalu mengatakan bahwa dia belum berniat berumah tangga.

Selanjutnya, diceritakan secara sorot balik pernikahan Halimah yang didampingi Nyi Asmanah. Dalam pernikahan itu Nyi Asmanah menjadi pusat perhatian dan dia setia menonton wayang sampai selesai; apalagi, lakonnya mengenai Dipati Arjuna, tokoh wayang yang dicintainya. Nyi Asmanah sungguh-sungguh menghayati pertunjukan wayang dan dia merasa tokoh Dipati Arjuna selalu memandang kepadanya. Bahkan, setelah wayang selesai, ceritanya terbawa ke alam mimpi dan tokoh Wara Subadra, istri Arjuna, berganti menjadi dirinya.

Karena bangun kesiangan, Nyi Asmanah baru tengah hari mandi di pancuran yang sudah sepi. Dia mandi seraya terus membayangkan Dipati Arjuna. Sepulang dari pancuran, ia melihat Arjuna di bawah pohon buah limus dan mengajaknya berbicara. Sejak itulah Nyi Asmanah sering berjumpa dengan Arjuna ketika dalam keadaan sepi dan sendiri. Kerap kali Arjuna mengajaknya ke Keraton untuk menikah. Hal itu berjalan setahun lebih semenjak dia menonton wayang. Jadi, kini umurnya sudah 18 tahun yang menurut orang kampung, Ni Asmanah sudah perawan tua. Ketika didesak oleh 
orang tuanya, dikatakannya bahwa dia hanya mau menikah dengan Arjuna yang sering menemuinya. Setelah kedua orang tuanya tahu kondisi Nyi Asmanah, dia kemudian terus diawasi agar tidak pergi ke pancuran sendiri.

Suatu malam dinihari dia mendengar musik seperti ada orang yang menanggap wayang dan terdengar juga suara Arjuna yang mengajaknya pergi dari rumah.Dia meninggalkan rumah dan kedua orang tuanya yang sedang tidur nyenyak. Dia sampai di suatu tempat dan bertemu dengan seorang kakek dari negeri siluman bernama Kakek Jamungkuk. Setelah di negeri siluman Nyi Asmanah merasa menjadi seorang puteri yang bernama Nyai Puteri Mayang Gading dan dia dinikahkan dengan pangeran siluman. Waktu Nyi Asmanah mengandung tujuh bulan bakal anaknya, tiba-tiba dia ingin makan buah limus. Setelah makan buah limus itu, ia sadar bahwa dirinya adalah Nyi Asmanah, bukan Nyai Puteri Mayang Gading, sehingga dia teringat ibu bapaknya. Dia meminta izin kepada suaminya untuk menengok orang tuanya. Suaminya memberikan izin, namun dengan syarat, Nyi Asmanah harus kembali sebelum tengah malam. Nyi Asmanah dapat melepas rindu dengan orang tuanya. Namun, tidak terasa waktu beranjak dengan cepat sehingga melampaui batas yang diberikan kepadanya sehingga ketika kembali ke negeri siluman, suaminya menolaknya. Nyi Asmanah terkatungkatung di antara alam siluman dan alam manusia. Akhirnya, bayinya keluar dari kandungannya dan diberi nama Burak. Burak adalah seorang anak laki-laki yang jika besar nanti akan berwajah tampan, tetapi kakinya menyerupai kaki kuda. Dia akan menjadi penggoda gadis yang berlama-lama mandi sendiri di pancuran ketika tengah hari.

\section{Skema Aktan Novel Sunda Burak Silu- man}

Setelah membaca novel secara saksama, dapatlah diketahui bahwa novel tersebut mengandung cerita berbingkai. Cerita mengenai Burak Siluman dikemukakan oleh tokoh Mang Ijan. Sementara itu, tokoh Mang Ijan hanya merupakan salah satu tokoh yang dikemukakan oleh si penutur dalam bingkai cerita. Oleh sebab itu, skema aktan dalam novel Burak Siluman terbagi dalam dua bagian, yaitu skema aktan "bingkai cerita" dan skema aktan "di dalambingkai cerita".

\section{Skema Aktan Bingkai Cerita}

Berikut ini adalah skema aktan yang terdapat dalam bingkai cerita yang terdapat dalam novel Burak Siluman dapat dilihat pada Gambar 1:

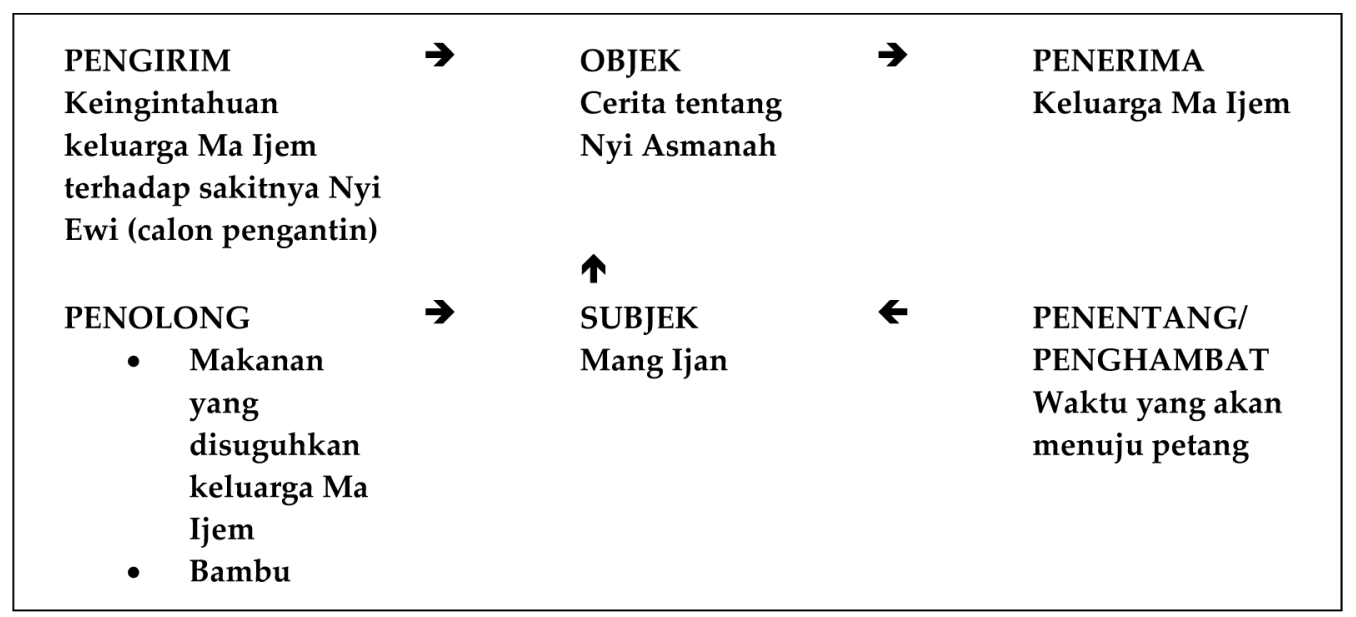

Gambar 1. Skema Aktan Bingkai Cerita 


\begin{tabular}{|lllll|}
$\begin{array}{l}\text { PENGIRIM } \\
\text { Pertunjukan Wayang }\end{array}$ & $\rightarrow$ & $\begin{array}{l}\text { OBJEK } \\
\text { Arjuna }\end{array}$ & $\rightarrow$ & $\begin{array}{l}\text { PENERIMA } \\
\text { Nyi Asmanah }\end{array}$ \\
PENOLONG & $\rightarrow$ & $\begin{array}{l}\text { SUBJEK } \\
\text { Nyi Asmanah }\end{array}$ & $\leftarrow$ & $\begin{array}{l}\text { PENENTANG/ } \\
\text { PENGHAMBAT } \\
\text { Kedua orang tua Nyi } \\
\text { Impian } \\
\text { tentang }\end{array}$ \\
$\quad \begin{array}{l}\text { Arjuna } \\
\text { Arjuna } \\
\text { Suara gong }\end{array}$ & & & \\
\hline
\end{tabular}

Gambar 2. Skema Aktan di dalam Bingkai Cerita

Skema aktan bingkai cerita menunjukkan bahwa tokoh Ijan sebagai subjek bertujuan untuk bercerita tentang Nyi Asmanah. Ijan sebenarnya hanya mengikuti kehendak keluarga Ma Ijem yang ingin mengetahui sakitnya Nyi Ewi. Oleh sebab itu, keluarga Ma Ewi dapat dianggap sebagai pengirim yang menggerakkan cerita. Mang Ijan bersemangat dalam bercerita karena keluarga Ma Ijem menyuguhkan makanan kesukaannya dan berharap pula mendapatkan bambu yang diperlukannya. Makanan dan bambu dapat berperan sebagai penolong, sementara aktan penghambat hanyalah waktu yang merangkak menuju petang. Penerima pekerjaan subjek (Mang Ijan) tentu saja keluarga Ma Ijem karena berdasarkan cerita tersebut, mereka jadi paham dengan sakit yang diderita Nyi Ewi.

\section{Skema Aktan di dalam Bingkai Cerita}

Berikut ini adalah skema aktan yang terdapat di dalam bingkai cerita novel Burak Siluman dan cerita utama cerpen "Burak Siluman" dapat dilihat pada Gambar 2.

Dalam skema aktan itu ditunjukkan bahwa tokoh Nyi Asmanah sebagai subjek ingin mendapatkan objek, yaitu Dipati Arjuna. Dalam teks novel diceritakan bahwa Nyi Asmanah sangat menyukai cerita wayang yang melakonkan Arjuna, keluarga penengah Pandawa yang gagah itu. Oleh sebab itu, aktan pengirim yang membuat subjek ingin mendapatkan objek adalah pertunjukan wayang golek. Dalam melunaskan keinginannya mendapatkan Arjuna, sebenarnya Nyi Asmanah mendapatkan hambatan dari kedua orang tuanya, yaitu Ki Jaka dan Nyi Sarwini. Akan tetapi, hambatan itu tidak menghalangi Nyi Asmanah untuk terus mencintai Dipati Arjuna yang selalu hadir dalam mimpi-mimpinya. Bahkan, dengan bantuan bunyi gong dan Dipati Arjuna sendiri yang menjemputnya, Nyi Asmanah berhasil mendapatkan keinginannya sehingga dia sampai pada kerajaan siluman, seperti tampak dalam penggalan berikut:

Tapi dina hiji peuting bet saking dumadak tengah peuting meujeuhna jempling nyi Asmanah lilir, kung...kung... dedengeannana sada goong wayang. Korejat hudang curinghak. Arjuna geus kadeleu bae."Nyai, Nyai!" cenah sadana ti buruan, sidik sora Arjuna. Nyi Asmanah teu ngurus dangdan heula, kojengkang $k a$ panto rek indit. Inget kana papakean nu dipake geus barelel, balik deui kana geledeg, capa-capa mapay bilik, waktu poek meredong (Ambri, 1950:97: 'Namun, pada suatu malam, bahkan tengah malam sunyi, secara tiba-tiba Nyi Asmanah terjaga, kung...kung... dia merasa mendengar gong wayang dibunyikan. Dia bangun seketika. Arjuna sudah muncul lagi. "Nyai, Nyai!" katanya terdengar di halaman, Jelas-jelas suara Arjuna. Nyi Asma- 
nah tak berpikir lagi, apalagi untuk merias diri, langsung menuju pintu untuk pergi. Dia baru ingat baju yang digunakannya sudah lusuh di sanasini, ia kembali lagi ke kamar dengan merambat menyusuri bilik rumah, malam gelap gulita')

Berikut ini kutipan serupa dari cerpen Ajip Rosidi:

Pada suatu malam, menjelang dinihari, Nyi Asmanah terjaga.Sepi keadaan sekeliling, bahkan jangkrik pun tak terdengar berdering. Tibatiba...kung...kung...kung...terdengar oleh Nyi Asmanah suara gung wayang dipukul dari kejauhan. Samar-samar terdengar pula suara gamelan. Tak syak lagi, suara gamelan wayang. Maka bangkitlah Nyi Asmanah dari tidurnya. Sekali lagi disimakkannya baik-baik, kalau-kalau telinganya salah.Tetapi nyata sekali suara gung yang bertalu-talu itu, seolah-olah memanggilnya.

Alangkah besar pengaruh suara gung itu padanya! Berbagai pikiran timbul dalam kepalanya. Sudah lama ia tidak menonton wayang. Dan Dipati Arjuna pun sudah lama tidak Nampak. Tentu akan bersua jika ia sekarang pergi menonton.

Sementara itu terdengar olehnya suara halus memanggil dari luar: “Nyai, Nyai, mari kita pergi!".Tak syak lagi itulah suara Dipati Arjuna. Perlahan-lahan ia bangkit, lalu dalam gelap meraba-raba mencari kain dan bajunya yang baru. Pakaiannya yang baik-baik disimpannya di dalam sebuah peti dipojok bilik. Ia tidak bisa memilih dalam gelap, tetapi dengan rabaan tangan dia jemput kain dan baju yang dirasanya paling baik... (Rosidi, 2008:178).

Penggalan novel Sunda dan cerpen Ajip menunjukkan kepada kita bahwa
Nyi Asmanah berposisi juga sebagai aktan penerima.

\section{Revitalisasi NovelSunda Burak Siluman ke dalam Cerpen Burak Siluman Aspek yang Direvitalisasi}

Untuk melihat aspek novel yang direvitalisasi, kita dapat melihat skema aktan yang terdapat dalam dua kaya tersebut. Skema aktan novel Sunda dan cerpen memiliki kesamaan, khususnya dalam skema aktan dalam-bingkai cerita. Dalam cerpen tidak terdapat bingkai cerita sehingga skema aktan dalam-bingkai cerita menjadi aktan utama. Jadi, dalam cerpen tidak terdapat tokoh Mang Ijan dan keluarga Ma Ijem sebab cerpen langsung pada skema aktan dalam-bingkai cerita, yaitu keluarga Nyi Asmanah.

Penghilangan bingkai cerita dalam cerpen dapat dipahami sebab cerpen, tentu saja, berbeda dengan novel. Stanton (2007:78-89) membedakan novel dengan cerpen dari panjang-pendeknya.Cerpen ceritanya lebih pendek sehingga harus ada pemadatan cerita.

Dalam pengantar novel Burak Siluman, Pengarang Utuy Tatang Sontani (Ambri, 1950) beranggapan bahwa tulisan Ambri sangat realis. Terlebih-lebih, bahasa yang digunakan Mohamad Ambri merupakan bahasa sehari-hari orang desa yang tanpa undak usuk basa.Bahkan, Utuy berkesimpulan bahwa Mohamad Ambri adalah pengarang Sunda yang memelopori aliran realisme (Sontani dalam Ambri, 1950:3). Penggunaan bingkai cerita pun menambah kerealisan cerita. Cerita tentang burak siluman yang merupakan mitos orang Sunda tidak dikisahkan langsung oleh narator atau pencerita, seperti kebanyakan cerita rakyat, melainkan oleh salah seorang tokoh, yaitu Mang Ijan.

Penggunaan teknik cerita berbingkai sebagai pemberi kesan realis dilakukan juga oleh Achdiat Kartamiharja dalam novel Atheis. Menurut kritikus Subagio Sastrowardoyo (Rosidi, 1977), teknik ce- 
rita berbingkai dalam Atheis berefek pada kuatnya objektivitas dan kadar realitas yang disuguhkan dalam novel tersebut sebab struktur cerita berbingkai memungkinkan realitas ditinjau tidak hanya dari satu sudut. Dengan berlakunya tinjauan yang lebih dari satu itu tercapai realitas yang lebih tinggi karena seolah-olah dunia novel diamati dan ditafsirkan lebih objektif dan juga lebih adil. Teknik cerita berbingkai yang dilakukan Mohamad Ambri untuk menonjolkan kesan realistis tampaknya tidak mengada-ada sebab semasa hidupnya dia bekerja di Balai Pustaka (1931-1936) dan selain menulis karya sastra asli berbahasa Sunda, dia pun menerjemahkan atau menyadur karya sastra dunia ke dalam bahasa Sunda, seperti Alf Layla wa Layla (Kisah Seribu Satu Malam) atau Si Kabayan Jadi Dukun (disadur dari karya dramawan Prancis, Moliere, yang berjudul Le Medecin Malgre Lui). Jadi, wawasan sastra yang mengglobal memungkinkan Mohamad Ambri melahirkan karya-karya Sunda yang modern pada zaman sebelum perang.

Sebaliknya, dalam cerpen Ajip Rosidi, karena bingkai cerita dihilangkan, kesan cerita rakyat jadi menonjol. Hal ini tampaknya disadari oleh Ajip Rosidi sehingga kumpulan cerpen tersebut tidak dinamakan kumpulan cerpen, melainkan kumpulan dongeng Sunda.

Jika kita memperhatikan riwayat kedua pengarang, Ajip Rosidi tentu saja lebih dahulu mengenal Mohamad Ambri ka-rena keduanya berbeda generasi, bahkan Mohamad Ambri telah meninggal (tahun 1936) sebelum Ajip Rosidi lahir (tahun 1938). Ajip Rosidi juga banyak menulis karyanya dalam bahasa Sunda. Oleh sebab itu, hal yang wajar apabila dia mengenali dan mengakrabi karya-karya Mohamad Ambri dalam karya sastra berbahasa Sunda. Akan tetapi, dalam cerpennya, Ajip Rosidi tampaknya tidak bermaksud untuk memperkenalkan aspek gaya penulisan Mohamad Ambri. Ajip lebih berupaya untuk menyelamatkan aspek cerita, khususnya tema cerita siluman sebagai salah satu mitos yang hidup dalam masyarakat Sunda buhun ('lama').

Penyajian cerita berbingkai dengan menggunakan tokoh orang desa sebagai pencerita berefek pada tenggelamnya peran pengarang sehingga pengaitan aspek biografis pengarang, seperrti yang dilakukan Kurnia (2008), tidak relevan dalam mengkaji novel ini. Demikian juga dalam cerpen, Ajip hanya menghilanglan bingkai cerita sehingga cerita cerpen serupa dengan dalam-cerita bingkai novel.

\section{Pola Revitalisasi}

Reaktualisasi novel Sunda Burak Siluman ke dalam cerpen berbahasa Indonesia senada dengan yang dilakukannya ketika Ajip Rosidi mentransformasi carita pantun Sunda Lutung Kasarung ke dalam bentuk prosa atau novel dengan judul Purba Sari Ayu Wangi. Dalam tesisnya, Pudentia M.P.S.S. (1990) menunjukkan bahwa tranformasi carita pantun ke dalam cerita rekaan atau novel dilakukan Ajip Rosidi dengan meminimalisasi dialog dan deskripsi yang merupakan ciri khas pantun sebagai sastra lisan yang ditembangkan. Sebaliknya, Ajip menonjolkan aspek penceritaan dari pencerita yang merupakan ciri khas dari sastra tulis. Akan tetapi menurut penulis, baik cerpen "Burak Siluman" maupun novel Purba Sari Ayu Wangi tetap memperlihatkan fungsi cerita sebagai penguat tradisi.

Dalam novel, tokoh Burak Siluman hanyalah seorang bayi yang baru dilahirkan oleh Nyi Asmanah. Setelah menikah dengan siluman (yang dianggapnya sebagai Dipati Arjuna), Nyi Asmanah berganti nama menjadi Nyi Mayang Gading, seperti tampak pada perkataan silumanyang dituturkan ayah Nyi Asmanah kepada para tetangganya :

Nyi Mayang Gading, eta orok ngaranna Burak, asuh $k u$ maneh, nepi ka sawawana, bawa longok-longokkeun ka 
unggal kolong, unggal jamban, jeung tampian. Panganten awewe anu ka cai tengah poe jeung parawan ngulampreng sorangan wanci sareupna hakaneunnana. Engke dina mangsana dewasa, Burak teh sipatna lalaki kasep, sampurna kakasepanna, bakal nyiliwuri di manusa, loba awewe nu kapincut. Tapi saha-saha nu awas kana sukuna moal kagoda sabab sukuna talapokan kuda (Ambri, 1950:119: ‘Nyi Mayang Gading, bayi ini bernama Burak, rawatlah sampai besar olehmu, bawa ke setiap kolong (rumah), ke setiap jamban, dan pancuran. Pengantin perempuan yang pergi ke pancuran pada tengah hari dan perawan yang ngelayap sendiri pada senjakala, itulah santapannya. Nanti ketika dia dewasa, Burak adalah jejaka yang sangat tampan, dia akan merasuki diri manusia, banyak perempuan yang kepincut. Namun, barang siapa yang sempat menatap kakinya, dia takkan tergoda sebab kakin ya menyerupai kaki kuda').

Demikian juga dalam cerpen Ajip Rosidi, kata-kata yang dikemukakan oleh Pangeran Siluman, suamiNyi Asmanah, serupa dengan novel Sundanya:

Nyi Mayang Gading, anak itu mesti kau beri nama Burak. Ia mesti kau asuh baik-baik hingga dewasa. Bawa ia ke tiap pancuran, ke tiap rumah, ke tiap jamban. Pengantin wanita yang pergi ke pancuran tengah hari dan perawan yang bepergian sendirian kala senja adalah hak menjadi mangsanya, kalau kelak ia sudah dewasa. Burak akan bisa campur dengan manusia, karena ia jejaka tampan yang menggiurkan dan akan banyak gadis-gadis yang tergoda hatinya. Tetapi mereka yang waspada tidak akan tergoda, karena kakinya tidaklah seperti kaki manusia, melainkan bertelapok seperti kaki kuda (Rosidi, 2008:207-208).
Berdasarkan penjelasan di atas dapat diketahui bahwa cerpen "Burak Siluman" karya Ajip Rosidi merupakan upaya revitalisasi yang terklasifikasi ke dalam pola rekonstruksi, yaitu menyelamatkan novel klasik Sunda agar tidak selamanya tertimbun dalam arsip khazanah sastra Sunda sehingga perlu disebarkan dalam media bahasa yang lebih luas, yaitu bahasa Indonesia. Selain itu, revitalisasi yang dilakukan Ajip dapat pula dikaitkan dengan upaya pewarisan khazanah sastra Sunda yang dalam kerangka World Bank (1995) berada pada pola transfer, yaitu dengan mengeksternalisasi, dalam hal ini mengalihbahasakan novel klasik Sunda tersebut ke dalam bahasa nasional agar pihak luar pun turut mengenal dan melestarikan cerita tesebut.

\section{Tujuan Revitalisasi}

Pola rekonstruksidalam revitalisasi biasanya dilakukan untuk karya seni yang sudah hilang dari peredaran, namun dianggap masih berpotensi untuk dihidupkan dan digiatkan kembali (Supanggah, 2008). Dalam pengantar buku atau kumpulan cerpen yang memuat cerpen "Burak Siluman", Ajip Rosidi mengatakan bahwa memang rencananya untuk "menuliskan kembali kesusastraan rakyat daerah yang dianggap bernilai dalam bahasa Indonesia dan menyuguhkan kepada lingkungan pembaca nasional, tidak hanya terbatas kepada para anggota suku bangsa yang memilikinya saja" (Rosidi, 2008:9). Dengan demikian, tujuan Ajip Rosidi mengalih wahana novel Burak Siluman bukanlah untuk memperkenalkan Mohamad Ambri yang cenderung bergaya realisme sepertri dikatakan Utuy Tatang Sontani, melainkan untuk mengonservasi cerita Sunda berkaitan dengan alam alam siluman.

\section{SIMPULAN}

Berdasarkan hasil dan pembahasan dapat disimpulkan bahwa revitalisasi 
novel klasik Sunda ke dalam cerpen Indonesia oleh Ajip Rosidi dilakukan dengan menghilangkan aspek cerita berbingkai sehingga cerpen tidak terlalu panjang dan tokoh yang membingkai cerita dihilangkan. Tidak adanya bingkai cerita dan peminimalan tokoh menghasilkan cerpen yang lebih dekat pada hakikatnya, yaitu pendek, padat, dan padu. Akan tetapi, yang dilakukan Ajip Rosidi berakibat pada luputnya gaya cerpen Mohamad Ambri yang cenderung beraliran realisme. Sebaliknya, cerpen tampak seperti cerita rakyat atau dongeng Sunda yang telah dialihbahasakan ke dalam bahasa nasional. Hal ini tampaknya wajar sebab Ajip Rosidi memang berupaya untuk menyelamatkan aspek cerita, khususnya tema cerita siluman sebagai salah satu mitos yang hidup dalam masyarakat Sunda buhun ('lama').

Revitalisasi yang yang dilakukan Ajip Rosidi terklasifikasi ke dalam pola rekonstruksi dan pola transfer, yaitu dengan melakukan eksternalisasi. Untuk kepentingan itulah Ajip Rosidi mengalihbahasakan novel klasik Sunda tersebut ke dalam bahasa nasional. Pola revitalisasi demikian, sebenarnya sekaligus menampakkan tujuan Ajip Rosidi mengalih wahana novel tersebut. Alih bahasa novel Sunda ke dalam cerpen Indonesia dilakukan Ajip Rosidi tidak untuk memperkenalkan Mohamad Ambri yang cenderung realis seperti dikatakan Utuy Tatang Sontani, tetapi untuk mengonservasi cerita Sunda berkaitan dengan mitos alam gaib atau alam siluman. Hasilnya dapatlah disimpulkan bahwa cerpen "Burak Siluman" Ajip Rosidi telah melakukan afirmasi atau pengukuhan terhadap mitos Sunda tersebut.

\section{UCAPAN TERIMA KASIH}

Artikel ini merupakan pengembangan dari disertasi saya. Oleh sebab itu, dengan penuh hormat saya mengucapkan terima kasih kepada Prof. Dr. Yus Rusyana, Prof.
Dr. Sapardi Djoko Damono, dan Almarhum Prof. Dr. Yoyo Mulyana, M.Ed. atas bimbingan dan saran-saran yang diberikan.

\section{DAFTAR PUSTAKA}

Adnan, Fatmahwati. 2015. “Tradisi Lisan Basesombau Melayu Tapung: Fungsi, Keterkaitan dengan Perilaku Masyarakat, dan Program Revitalisasi". Disertasi. Sekolah Pascasarjana Universitas Pendidikan Indonesia Bandung.

Ambri, Mohamad. 1950. Urang Desa. Jakarta: Balai Pustaka.

Kamus Besar Bahasa Indonesia. 2013, Edisi ke-4. Jakarta: Depdikbud RI.

Kurnia, Atep. 2008. "Siluman dalam Sastra Sunda". Pikiran Rakyat. 28 Juni.

Moleong, Lexy J. 2005. Metodologi Penelitian Kualitatif. Bandung: PT Remaja Rosda Karya.

Pudentia M.P.S.S. 1990. “Transformasi Sastra: Analisis atas Cerita Rakyat Lutung Kasarung". Tesis. Fakultas Pascasarjana Universitas Indonesia Jakarta. Pudentia M.P.S.S. 2010. “The Revitalization of Makyong in the Malay World". Jurnal Wacana. Volume 12 No. 1. April 2010. Jakarta: Universitas Indonesia.

Ratna, Nyoman Kutha. 2004. Teori, Metode, dan Teknik Penelitian Sastra. Yogyakarta: Pustaka Pelajar.

Rosidi, Ajip. 1977. Laut Biru Langit Biru. Jakarta: Pustaka Jaya.Rosidi, Ajip. 1996. Pancakaki: Kumpulan Esay. Bandung: Girimukti Pusaka.

Rosidi, Ajip. 2008a. Hidup Tanpa Ijazah: yang Terekam dalam Kenangan. Jakarta: Pustaka Jaya.

Rosidi, Ajip. 2008b. Jalan ke Surga atawa Si Kabayan. Bandung: Nuansa.

Rusyana, Yus. 1979. Novel Sunda Sebelum Perang. Jakarta: Pusat Bahasa

Stanton, Robert. 2007. Teori Fiksi Robert Stanton. (Diterjemahkan oleh Sugihastuti dan R.A. Al Irsyad). Yogyakarta: Pustaka Pelajar. 
Sumiyadi. 2010. “Pengkajian dan Pengajaran Sastra Indonesia Berbasis Sastra Bandingan." Disertasi. Sekolah Pascasarjana Universitas Pendidikan Bandung.

Supanggah, Rahayu. 2008. "Kesenimanan dalam Revitalisasi Kesenian”. Htpp:// tradisilisan/ blogspot.co.id/2008/04/ kesenimanan-dalam-revitalisasi- kesenian_html?m=1. Diunduh 20 Februari 2016

World Bank. 1988. "Indogenues Knowledge for Development a Frame Work for Action". Africa: Knowlwdge and Learning Center Africa Region

Zaimar, Okke KS. 2014. Semiotika dalam Analisis Karya Sastra. Depok: Komodo Books 